part in the determination of a characteristic estimates of heritability derived from values of ${ }^{\mathrm{r}} \mathrm{MZ},{ }^{2 \mathrm{r}} \mathrm{DZ}$, and $2\left({ }^{\mathrm{r}} \mathrm{MZ}-{ }^{\mathrm{r}} \mathrm{DZ}\right)$ will be the same (see methods). The reverse is also true: if estimates of heritability calculated by the three methods are similar the contribution of common family environment must be small. The heritabilities calculated by the three methods were similar in older twins, but the discrepancies between them in the younger twins indicate that the influence of common family environment is strongest at this age. Parental influence over food intake is greatest in younger children, and we presume this accounts for the high contribution of family environment to the variation of total body fatness in younger children which overrides the genetic contribution observed in older children.

There were few obese twins in our series and no special study was made of them. Nevertheless, our findings have implications for the aetiology of obesity. The part played by over-nutrition in infancy in the subsequent development of obesity has been much debated. Our results suggest that in younger children environmental influences largely determine the variation in body fatness and imply that body fatness can be readily affected by changes in diet. In older children, however, the alteration of a characteristic so strongly genetically determined will be much more difficult and will demand great environmental adjustmentc. Our results may go some way towards explaining why th. treatment of obesity in older children is so difficult and so ofter unsuccessful.
We thank Dr. C. O. Carter, Professor J. M. Tanner, and Dr. Charles Smith for their helpful comments on the manuscript.

Requests for reprints should be addressed to Dr. C. G. D. Brook.

\section{References}

1 Durnin, J. V. G. A., and Rahaman, M. M., British fournal of Nutrition 1967, 21, 681.

2 Brook, C. G. D., Archives of Disease in Childhood, 1971, 46, 182.

3 Shields, J., Monozygotic Twins Brought up Apart and Brought up Together, London, Oxford University Press, 1962.

4 Tanner, J. M., and Israelsohn, W. J., Annals of Human Genetics, 1963, 26, 245.

${ }^{5}$ Osborne, R. H., and de George, F. V., Genetic Basis of Morphological Variation, Cambridge, Mass., Harvard University Press, 1959.

${ }^{6}$ Huntley, R. M. C., Ph.D. Thesis, London, 1966.

7 Edwards, D. A. W., et al., British fournal of Nutrition, 1955, 9, 133.

Tanner, J. M., and Whitehouse, R. H., British Medical fournal, 1962, 1, 446.

${ }^{9}$ Snedecor, G. W., and Cochran, W. G., Statistical Methods, Iowa State University Press. 6th Edition, 1967.

10 Tanner, J. M., and Whitehouse, R. H., Archives of Disease in Childhood, $1975,50,142$.

${ }^{11}$ Falconer, D. S., Introduction to Quantitative Genetics, p. 165. Edinburgh, Oliver and Boyd, 1960

12 Armitage, P., in Statistical Methods in Medical Research, p. 160. Oxford, Blackwell Scientific Publications, 1971.

${ }^{13}$ Huntley, R. M. C., in Genetic and Environmental Factors in Human Ability. ed. S. E. Meade and A. S. Parkes. Edinburgh, Oliver and Boyd, 1966. 14 Pariskova, J., and Roth, Z., Human Biology, 1972, 44, 613.

\title{
Probabilistic Application of Plasma Carcinoembryonic Antigen Assay in Cancer Patients
}

\author{
LEONIE K. ASHMAN, J. LUDBROOK, V. R. MARSHALL
}

British Medical fournal, 1975, 2, 721-724

\begin{abstract}
Summary
Plasma carcinoembryonic antigen (C.E.A.) levels in inpatients proved at necropsy to be cancer free were used to assess the ability of the C.E.A. assay to distinguish benign and malignant disease. The patients had a mean C.E.A. level significantly greater than that for young healthy people. In view of the considerable overlap of the ranges of plasma C.E.A. concentration in cancer patients and patients with non-malignant disease a probabilistic interpretation is advocated rather than the use of a simple cut-off between positive and negative. On the basis of the cancer-free control group, 19 out of 64 untreated patients with various solid tumours had plasma C.E.A. levels considered to correspond to a greater than $95 \%$ probability of cancer.
\end{abstract}

\section{Introduction}

Despite encouraging early results ${ }^{1}$ the assay of plasma or serum carcinoembryonic antigen (C.E.A.) is now known to be nonspecific as a test for cancer of the digestive tract. Raised plasma

\footnotetext{
Department of Surgery, University of Adelaide, Adelaide 5000, South Australia

LEONIE K. ASHMAN, PH.D., Senior Research Officer

J. LUDBROOK, M.D., F.R.A.C., Professor of Surgery

J. LUDBROOK, M.D., F.R.A.C.S., Professor of Surgery
}

C.E.A. levels are associated with various non-gastrointestinal malignancies, chronic liver disease, and inflammatory diseases of the bowel and lung. ${ }^{2-5}$ Since C.E.A. which is immunologically identical with that from tumour tissue is present in the plasma of normal healthy adults ${ }^{6}$ it cannot be considered tumourspecific, and further refinement of the assay reagents may not eliminate these "false-positive" results.

If the C.E.A. assay is to be useful for the diagnosis of cancer, then it will be necessary to use it quantitatively and in relation to appropriate control groups, rather than by setting an arbitrary division between normal and abnormal based on levels in young healthy people. In an attempt to establish a more appropriate control group we set out to use C.E.A. levels in inpatients proved after death to be cancer free as the basis against which to compare levels in cancer patients.

\section{Subjects, Materials, and Methods}

\section{SAMPLE COLLECTION AND SELECTION}

Blood was collected in $10-\mathrm{ml}$ tubes containing $15 \mathrm{mg}$ dipotassium EDTA, and cells were removed by gentle centrifugation within four hours. Plasma samples were frozen and stored at $-20^{\circ} \mathrm{C}$.

Plasma samples from 114 people in the following three groups were assayed. (1) A control group of healthy young adults consisting of 27 laboratory workers and medical students with a mean age of $24 \cdot 1 \pm 1 \cdot 0$ years and a male to female ratio of $1 \cdot 1: 1$. (2) A second control group consisting of 23 patients selected from 220 inpatients with various potentially lethal conditions. These patients were chosen because they subsequently died and were shown at necropsy to be free from malignant disease. The causes of death were circulatory disease (8), multiple trauma (5), pneumonia (5), viral encephalitis (2), alcoholic cirrhosis (1), alcoholic hepatitis (1), and benign gastric ulcer (1). The mean 
age for the group was $59.5 \pm 3.9$ years and the male to female ratio $2 \cdot 8: 1$. (3) sixty-four cancer patients with tumours originating in the lung (22), colon (14), rectum (10), prostate (7), pancreas (6), and stomach (5). Only untreated patients in whom the diagnosis was subsequently confirmed by biopsy or at operation or necropsy were included. Their mean age was $68 \cdot 4 \pm 11.0$ years and their male to female ratio $2 \cdot 2: 1$.

\section{ANTIGEN AND ANTISERUM}

C.E.A. was prepared from liver metastases derived from primary colonic carcinoma by the method of Krupey et al. ${ }^{7}$ The product, identified by its reaction on immunodiffusion with antiserum from Hoffmann-La Roche (goat No. 23), was used to raise antisera in rabbits. Antiserum was selected for its lack of reactivity on gel diffusion and radioimmunoassay with the lower molecular weight cross-reacting glycoprotein which is present in $\mathrm{HClO}_{4}$ extracts of human lung ${ }^{8}$ and used without absorption. ${ }^{125}$ I-C.E.A. was prepared by the chloramine $\mathrm{T}$ method $^{9}$ and freed from breakdown products by Sephadex G200 chromatography.

Our purified C.E.A. was immunologically indistinguishable from Roche standard C.E.A., based on the slopes of logit-transformed radioimmunoassay standard curves, irrespective of whether our own or Roche antiserum and ${ }^{125}$ I-C.E.A. were used. Our preparation, however, had only $54 \%$ as much immunological activity per unit weight as that stated for the Roche standard. The difference may have been due to the water content of our C.E.A., since no measures were taken to ensure that it was anhydrous. For simplicity we have expressed our results in Roche C.E.A. units.

\section{RADIOIMMUNOASSAY PROCEDURES}

Plasma samples from all subjects were assayed in duplicate for C.E.A. in double-blind fashion in our laboratory using our own reagents, and at the Institute of Medical and Veterinary Science, Adelaide, using the Roche kit assay. ${ }^{* 10}$ In our laboratory plasma samples were extracted with $1 \mathrm{M} \mathrm{HClO}_{4}$, centrifuged, and the supernatants dialysed against $0.01 \mathrm{M}$ TRIS $\left(\mathrm{Cl}^{-}, \mathrm{pH} 7.5\right)$ before assay by a micromethod based on that of MacSween et al. ${ }^{11}$ and requiring only $0.05 \mathrm{ml}$ of extracted plasma. Free antigen and antigen bound to antibody were separated by $50 \%$ saturated $\left(\mathrm{NH}_{4}\right)_{2} \mathrm{SO}_{4}$ fractionation, and radioactivity in the washed pellets was determined. $\mathrm{HClO}_{4}$-extracted C.E.A.-free plasma to serve as diluent for the C.E.A. standards was prepared by treating pooled normal human plasma with 100 -fold excess of anti-C.E.A.-Sepharose 4B immunoadsorbent for 24 hours at $25^{\circ} \mathrm{C}$ before acid extraction. A trial run in which a trace amount of ${ }^{125}$ I-C.E.A. was preincubated with the plasma before the immunoadsorbent treatment indicated essentially complete removal of C.E.A. from plasma by this method. Radioimmunoassay inhibition curves for standard C.E.A. serially diluted in different batches of C.E.A.free plasma showed negligible variation.

Duplicate assays were carried out in separate batches for our procedure, and in the same batch for the Roche method. The average error between replicates was $9.4 \%$ by our assay procedure and $8.3 \%$ by the Roche assay. Samples for which the error between replicates exceeded $20 \%$ were re-assayed. The correlation coefficient for results of the two assay methods was $0 \cdot 71$.

\section{DATA ANALYSIS}

In this report \pm indicates the standard error of the mean. Means for the two control groups were compared by using Students' $t$ test for unpaired data. Confidence limits and probability bands were calculated on the assumption that levels of plasma C.E.A. were normally distributed in each control group. This assumption was tested with the $\chi^{2}$ test. $^{12}$

\section{Results}

CONTROLS

The results of C.E.A. determination on plasma samples from the two control groups by both assay procedures are shown in fig. 1 . With our

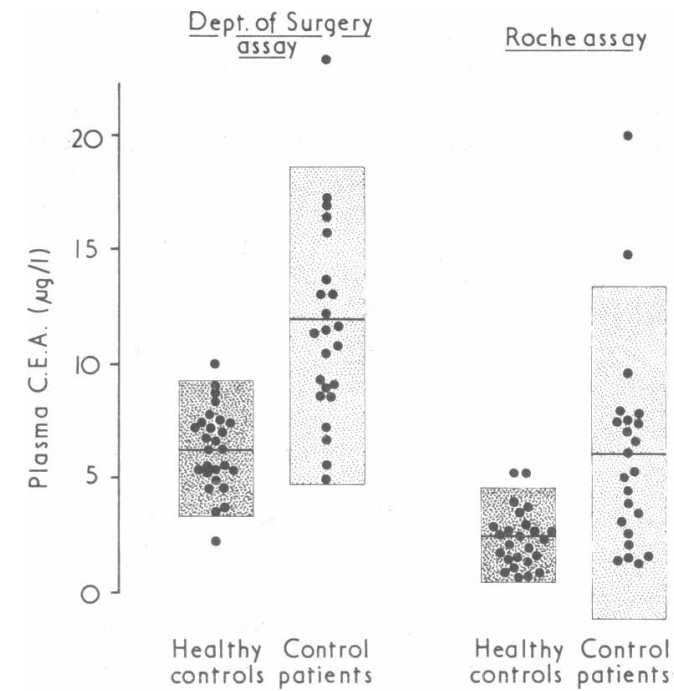

FIG. 1-Plasma C.E.A. levels in controls. Shaded areas indicate $90 \%$ confidence limits for the two groups by the two assay procedures (see text).

assay procedure the mean plasma C.E.A. concentration in the healthy controls was $6.30 \pm 0.34 \mu \mathrm{g} / \mathrm{l}$. For the same group the Roche assay, which uses a different baseline, gave a mean of $2.42 \pm 0.23 \mu \mathrm{g} / \mathrm{l}$. In neither case did the distribution differ significantly from normal ( $P=0.60$ for our assay data; $P=0.35$ for the Roche assay data).

By both procedures the cancer-free control patients were found to have a significantly $(P<0.001)$ greater mean C.E.A. level than the healthy people $(11.6 \pm 0.9 \mu \mathrm{g} / 1$ by our assay; $5.9 \pm 0.9 \mu \mathrm{g} / 1$ by the Roche assay). The values obtained by our assay approximated a normal distribution $(\mathbf{P}=0.76)$ for this group; however, data obtained with the Roche assay conformed poorly to a normal distribution $(\mathrm{P}<0 \cdot 1)$ and displayed positive skew with compression of the lower end of the range.

\section{CANCER PATIENTS}

C.E.A. concentrations in the plasma from cancer patients are shown in fig. 2 in relation to the levels found in the control groups. Of the 64 cancer patients, 19 by our assay and 18 by the Roche assay had plasma C.E.A. levels above the upper $90 \%$ confidence limit for the cancer-free patient control group. Sixteen patients had levels exceeding this limit by both assays, three by our assay only, and two by the Roche assay only. When compared with the healthy controls, 50 of the cancer patients by our assay and 44 by the Roche assay had C.E.A. levels above the upper $90 \%$ confidence limit for this group. Confidence

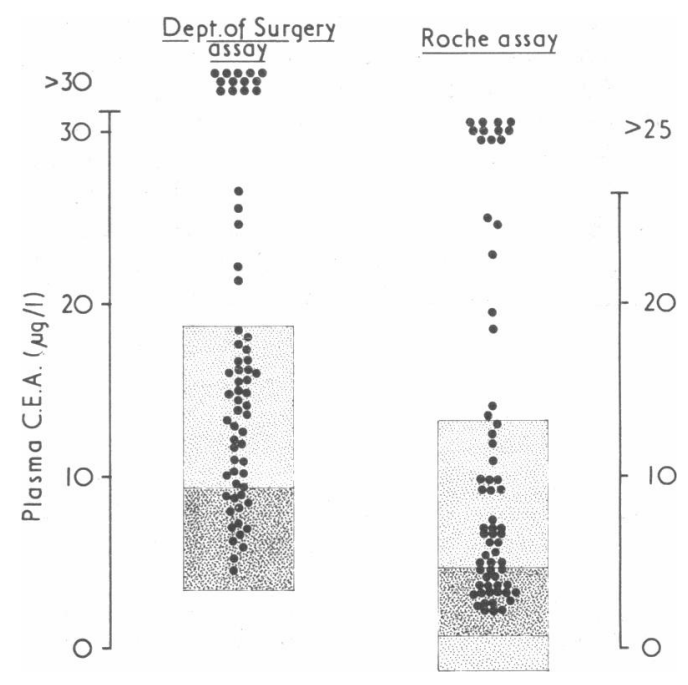

FIG. 2-Plasma C.E.A. levels in cancer patients. Shaded areas indicate $90 \%$ confidence limits for healthy control group (dark shading) and control patients who came to necropsy (light shading) (from data in fig. 1). 
limits for the control patient group by the Roche assay are only approximate, since the calculation assumed normal distribution of the data. The number of patients in the group was insufficient for an adequate non-parametric analysis but, in a simple ranking comparison, 22 of the 64 cancer patients by our assay and 16 by the Roche assay had C.E.A. levels above the 90th percentile of the cancer-free patient group.

On the basis of the data from the cancer-free patient control group using our assay method we calculated the probability of a patien having cancer for a particular C.E.A. level. The plasma C.E.A. levels in the 64 cancer patients subdivided according to the site of origin of the tumour are shown in relation to these diagnostic probability bands in fig. 3. The results confirm the lack of specificity of the C.E.A. assay for gastrointestinal cancer. Of the 19 patients who had plasma C.E.A. levels corresponding to a better than $95 \%$ probability of cancer, three (all colorectal cancer patients) had disease confined to the organ of origin, four had lymph node involvement, and 12 had distant metastases.

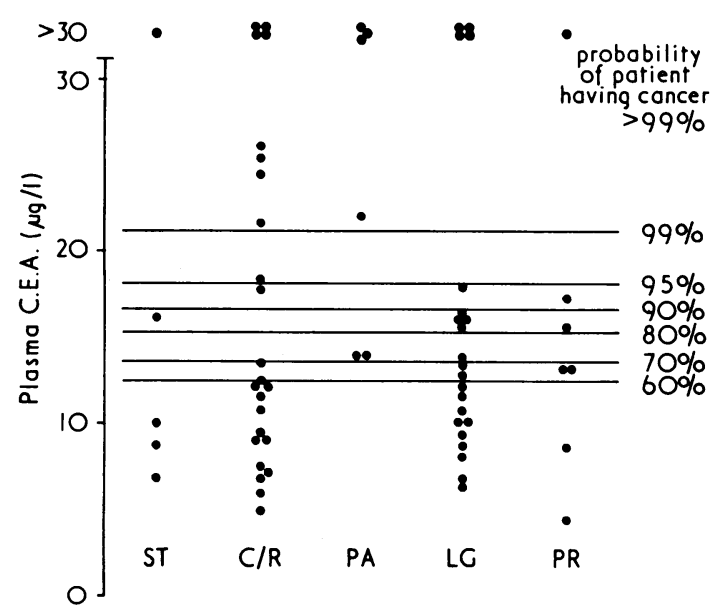

FIG. 3-Diagnostic reliability of C.E.A. assay for tumours at different sites. Data obtained with department of surgery C.E.A. assay. Probability bands were calculated from C.E.A. levels in control patients who came to necropsy, assuming a normal distribution. $\mathrm{St}=\mathrm{Stomach} . \mathrm{C} / \mathrm{R}=\mathrm{Colon}$ or rectum. $\mathrm{PA}=$ Pancreas. $\mathbf{L G}=$ Lung. $\mathrm{PR}=$ Prostate.

\section{Discussion}

Though many workers have reported that patients with various benign conditions have plasma C.E.A. levels considerably above those found in young healthy adults, little attempt has been made to analyse the distribution of C.E.A. levels in such patients in a way which would enable quantitative and probabilistic interpretation of the results of the C.E.A. assay to be made. One problem with such an analysis is the difficulty of ensuring that a patient with a benign condition does not have a coexisting malignant lesion which is not clinically evident, particularly since some conditions (such as ulcerative colitis) which give high plasma C.E.A. levels are associated with a significant incidence of malignancy. We sought to overcome this problem by using as a control group patients who subsequently died and were shown at necropsy to be cancer free.

The assay procedure developed in this laboratory enables a more meaningful analysis of the distribution of plasma C.E.A. levels in the different groups to be made than is possible by other methods. Commonly employed C.E.A. assay methods use either a buffer ${ }^{13}$ or pooled normal plasma or serum, extracted with $\mathrm{HClO}_{4}$ where applicable ${ }^{1}$ as diluent for the C.E.A. standards. The former take no account of the non-specific effect of other plasma constituents on the assay, ${ }^{14}$ whereas the latter measure only C.E.A. concentrations in excess of those found in pooled normal plasma. In the Roche assay, standards and unknowns are dissolved in different buffer systems, and the EDTA buffer standard curve is adjusted in some laboratories ${ }^{2}$ to conform to a zero normal human plasma baseline. In contrast, the assay procedure developed in this laboratory using as the baseline $\mathrm{HClO}_{4}$-extracted pooled normal human plasma specifically freed of C.E.A. by immunoadsorbent treatment enables the actual C.E.A. concentrations to be measured.

The mean plasma C.E.A. concentration determined in healthy young adults by this method was $6.3 \mu \mathrm{g} / \mathrm{l}$, which should be a more accurate estimate of the true normal plasma C.E.A. content than is obtained with other assay procedures. We have confirmed (unpublished results) the finding of $\mathrm{Chu}$ et al. $^{6}$ that the C.E.A. in normal plasma is immunologically identical, based on radioimmunoassay inhibition data, with that from tumour tissue. By comparison the mean concentration for the same subjects by the Roche assay was $2.4 \mu \mathrm{g} / \mathrm{l}$ (which is only marginally below the level $(2.5 \mu \mathrm{g} / \mathrm{l})$ often accepted as the upper limit of normal for the assay). The normal range for the modified Egan assay, in which a buffer baseline is used, is considered to be $0-12.5 \mu \mathrm{g} / 1 .{ }^{15} 16$

Our results confirm that there is considerable overlap of the ranges of plasma C.E.A. concentration in cancer patients and patients free from malignant disease. The cancer-free inpatient group had a mean C.E.A. level greatly exceeding that for the healthy young adults. We believe that the former group, which had a similar age and sex distribution to the cancer patient group, provides the more appropriate basis for assessment of the significance of particular plasma C.E.A. levels in terms of the probability that a patient has cancer. For this group the upper $90 \%$ confidence limit (C.E.A. levels above which would correspond to a greater than $95 \%$ probability of cancer) was $18.6 \mathrm{pg} / 1$ for our assay and $13.2 \mu \mathrm{g} / \mathrm{l}$ for the Roche assay. Of the cancer patients, who were chosen because they were previnusly untreated in order to simulate diagnosis in real life, about onethird by either assay procedure had plasma C.E.A. levels above these values. High C.E.A. levels were found with all types of cancer studied. In contrast, when the healthy young adults were used as controls $78 \%$ of the cancer patients (by our assay) had a C.E.A. level corresponding to an apparently greater than $95 \%$ probability of cancer. On this basis, however, $65 \%$ of the cancer-free inpatients also appeared to have a greater than $95 \%$ probability of cancer. Clearly from these results the use of control groups of young healthy people leads to an unacceptable rate of false-positive results.

The results obtained with cancer patients and with patients suffering from non-malignant disease illustrate the need for great care in designating moderately raised plasma levels as positive or negative. A better approach is to express the results in probabilistic terms, then the clinician can interpret the result in the light of other available information.

Collection of plasma samples from suitable control patients is continuing in this laboratory to enable better definition of the distribution of C.E.A. levels in this group to be made. These cancer-free patients have been selected at random with respect to the nature of their disease; as more data become available it will be possible to examine C.E.A. levels associated with different non-malignant conditions and in different age groups.

We are grateful to Mr. T. D. Geary, division of clinical chemistry, Institute of Medical and Veterinary Science, Adelaide, for carrying out the Roche C.E.A. assays on our samples. In addition, we wish to acknowledge the help of Mr. A. J. McPhee and Mr. P. W. E. Clark in the collection of blood samples, and the technical work of Mrs. D. E. Cowling.

This work was supported by grants from the National Health and Medical Research Council of Australia, and the University of Adelaide Anti-Cancer Foundation.

\section{References}

1 Thomson, D. M., et al., Proceedings of the National Academy of Sciences, $1969,64,161$

Kupchik, H. Z., Zamcheck, N., and Saravis, C. A., Fournal of the National Cancer Institute, 1973, 51, 1741

3 Meeker, W. R., et al., Archives of Surgery, 1973, 107, 266.

1 Hansen, H. J., et al., Human Pathology, 1974, 5, 139.

5 Khoo, S. K., Medical fournal of Australia, 1974, 1, 1025. 
6 Chu, T. M., Reynoso, G., and Hansen, H. J., Nature, 1972, 238, 152.

${ }^{7}$ Krupey, J., et al., Immunochemistry, 1972, 9, 617.

8 Kleist, S. von, Chavanel, A., and Burtin, P., Proceedings of the National Academy of Sciences, 1972, 69, 2492.

Academy of Sciences,
9 Weir, 608. Oxford, Blackwell, 1967.

${ }^{10}$ Chu, T. M., and Reynoso, G., Clinical Chemistry, 1972, 18, 918.
${ }^{11}$ MacSween, J. M., et al., British fournal of Cancer, 1972, 26, 356.

12 Snedecor, G. W., and Cochran, W. G., Statistical Methods, 6th edn, p. 84. Iowa State University Press, 1967. Ames, Iowa.

13 Egan, M. L., et al., Immunochemistry, 1972, 9, 289.

14 Pustaszeri, G., and Mach, J. P.. Immunochemistry, 1973, 10, 197.

15 Laurence, D. J. R., et al., British Medical fournal, 1972, 3, 605.

16 Booth, S. N., et al., Gut, 1973, 14, 794.

\title{
Antinuclear Antibodies in Psychiatric Illness: Their Relationship to Diagnosis and Drug Treatment
}

\author{
EVE C. JOHNSTONE; K. WHALEY
}

British Medical fournal, 1975, 2, 724-725

\begin{abstract}
Summary
Antinuclear antibodies occurred more often and in higher titres in psychiatric patients than in controls. Anti-DNA antibodies were not found. We suggest that antinuclear antibodies may be drug-induced and that lithium carbonate may have a particular tendency to produce this reaction.
\end{abstract}

\section{Introduction}

Psychiatric abnormalities are common in patients with systemic lupus erythematosus (S.L.E.). ${ }^{1-4}$ They may occur early and form part of the presenting picture. ${ }^{5}$ The features vary, and though the picture is often that of an organic psychosis, presentations typical of functional psychoses and neurotic illnesses occur. ${ }^{4}$ Our recent experience was in keeping with this finding, in that on several occasions a diagnosis of S.L.E. was made in patients who had initially presented psychiatrically. This caused us to consider what the true incidence of S.L.E. in psychiatric practice might be, as it is normally regarded as rare. Several drugs induce S.L.E. or a condition closely resembling it. Notable in this respect is hydrallazine ${ }^{6}$ but other drugs including procainamide ${ }^{7}$ and some anticonvulsants ${ }^{8}$ have similar effects. Clearly drug ingestion would be relevant to the study of the incidence of features suggestive of S.L.E.

We therefore studied the incidence of serological evidence of S.L.E. in 100 patients with acute psychiatric conditions as compared with controls and considered the relationship between the presence of antinuclear factor (A.N.F.) and (a) the psychiatric diagnosis and $(b)$ the drug history.

\section{Method}

Ninety-two inpatients and eight day patients at an acute general hospital psychiatric unit were studied; 71 were women and 29 men and their mean age was 45 years. The mean length of time since their first psychiatric attendance was 48.24 months. Altogether 110 diagnoses were put forward (see table II). The current drug regimens and those of the previous year are shown in table III. All patients gave a sample of venous blood, from which serum was separated and stored

\section{University of Glasgow}

EVE C. JOHNSTONE, M.R.C.P., M.R.C.PSYCH., Lecturer in Psychological Medicine (Now Member of Scientific Staff, Division of Psychiatry, Clinical Research Centre, Middlesex)

K. WHALEY, M.D., M.R.C.PATH., Lecturer in Immunopathology (Now Instructor in Medicine, Division of Immunology and Connective Tissue Diseases, Medical College of Virginia, Richmond, Virginia, U.S.A.) at $-20^{\circ} \mathrm{C}$ until used. All sera were tested by immunofluorescence for A.N.F. ${ }^{9}$ in one batch. Sera were screened at a titre of $1 / 16$ and then titred at quadrupling dilution until an end-point of staining was achieved. Sera containing A.N.F. were tested for DNA antibodies by a modification ${ }^{10}$ of the ammonium sulphate precipitation technique of Pincus et al. ${ }^{11}$

Sera from 112 osteoarthritic patients matched for age and sex with the psychiatric patients were used as controls.

\section{Results}

The results of the serological investigations are shown in table I. The diagnoses of the patients with A.N.F. are shown in table II. No single diagnosis was clearly associated with the presence of A.N.F. but there was a tendency for patients with A.N.F. to be psychotic rather than neurotic. In the entire patient sample 51 of the 110 diagnoses made were of psychotic as opposed to neurotic illness, while in the patients with A.N.F. 17 out of 27 diagnoses were of psychosis rather than neurosis $(\mathbf{P}>0.05)$.

The drug regimens of the patients with A.N.F. are shown in table III. There was a tendency for patients on lithium to have A.N.F. Seven patients in the study were on lithium. Of these, four had A.N.F., and in three of these the titre was $1 / 64$ or greater (see fig.). This tendency to high titres of A.N.F. in patients on lithium as opposed to the remainder of the sample is statistically significant $\left(\chi^{2}=9 \cdot 52\right.$; $\mathrm{P}<0.01)$. Table III also shows that the patients with A.N.F. tended to be on "other drugs." These varied greatly and were generally for intercurrent disease, mainly not affecting the central nervous system. DNA antibodies were not found in any of the sera.

TABLE I-Results of Serological Tests for A.N.F.

\begin{tabular}{lll|c|c}
\hline \multicolumn{2}{c|}{ Results } & & $\begin{array}{c}\text { Psychiatric Patients } \\
(\mathrm{n}=100)\end{array}$ & $\begin{array}{c}\text { Controls } \\
(\mathrm{n}=112)\end{array}$ \\
\hline Negative $\because$ \\
Weakly positive $\ldots$ & $\ldots$ & $\ldots$ & 75 & 96 \\
Strongly positive at & $1 / 16 \ldots$ & $\ldots$ & 8 & 10 \\
Positive at over $1 / 16$ & $\ldots$ & $\cdots$ & 10 & 6 \\
\end{tabular}

$\chi^{2}=10 \cdot 16 ; P<0.02$.

DNA antibodies were not found in any of the patients.

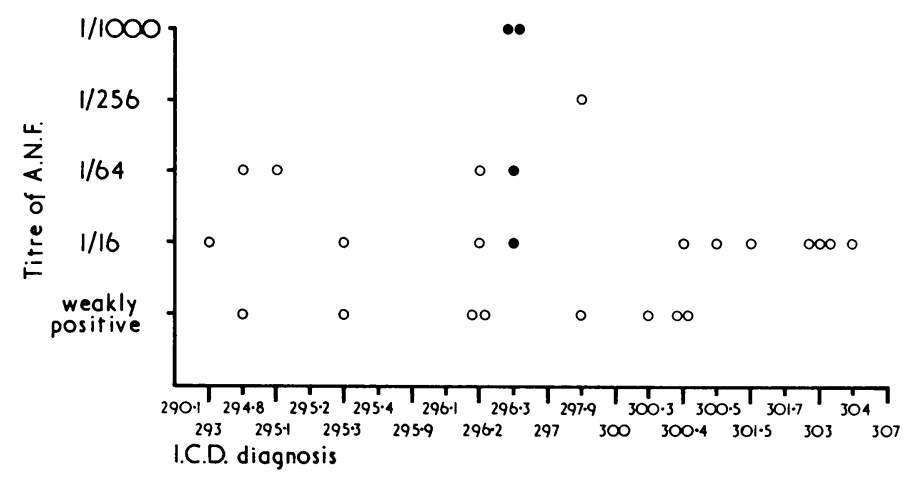

Relationship between A.N.F. titre and I.C.D. diagnosis (see table II for key). $=$ Patients on lithium. $\mathrm{O}=$ Patients on any other drug. 